Research Article

\title{
Sodium Dodecylbenzene Sulfonate-Modified Biochar as An Adsorbent for The Removal of Methylene Blue
}

\author{
Argo Khoirul Anas*), Sandy Yudha Pratama, Aqidatul Izzah, Muhammad Arsyik Kurniawan \\ Department of Chemistry, Universitas Islam Indonesia, Yogyakarta, 55581, Indonesia.
}

Received: $8^{\text {th }}$ February 2021; Revised: 23rd March 2021; Accepted: $23^{\text {rd }}$ March 2021

Available online: 25th March 2021; Published regularly: March 2021

\section{Abstract}

Biochar is an interesting adsorbent material due to its use is correlated with biomass waste utilization and also minimize environmental pollution from high amount of biomass by-product. Regarding to improve the biochar ability in water treatment, several surface modifications have been developed, one of them is modification using surfactant. In this study, sodium dodecylbenzene sulfonate (SDBS) was used to modify the surface of biochar prepared from pyrolysis of cassava peels (Manihot utilissima). Its performance in biochar modification to remove methylene blue (MB) dyes was compared with sodium dodecyl sulphate (SDS) surfactant for observing the important of $\pi-\pi$ interactions mechanisms. The analysis of biochar and biochar-SDBS were conducted by using Fourier transform infrared (FTIR), CHNS elemental analysis, and scanning electron microscope (SEM). Furthermore, the adsorption experiments were conducted using UV-Vis spectrophotometer. It is known that modification using SDBS could increase the adsorption capacity of biochar not only from electrostatic interaction but also through $\pi-\pi$ interactions mechanisms. In this respect, as the amount of SDBS mass increased, the adsorption capacity was also improved due to the modification produced more active cites on biochar. The maximum MB adsorption onto biochar-SDBS occurred at adsorbent mass of $15 \mathrm{mg}$ with optimum $\mathrm{pH}$ value of 10 .

Copyright (C) 2021 by Authors, Published by BCREC Group. This is an open access article under the CC BY-SA License (https://creativecommons.org/licenses/by-sa/4.0).

Keywords: Biochar; Cassava Peels; Surfactant; Sodium Dodecylbenzene Sulfonate (SDBS); Methylene Blue

How to Cite: A.K. Anas, S.Y. Pratama, A. Izzah, M.A. Kurniawan (2021). Sodium Dodecylbenzene SulfonateModified Biochar as An Adsorbent for The Removal of Methylene Blue. Bulletin of Chemical Reaction Engineering \& Catalysis, 16(1), 188-195 (doi:10.9767/bcrec.16.1.10323.188-195)

Permalink/DOI: https://doi.org/10.9767/bcrec.16.1.10323.188-195

\section{Introduction}

Biochar is a kind of porous carbon material which mainly produced from biomass through pyrolysis process [1]. It has several advantages such as environmental-friendly, low cost, easy preparation, and has a high surface area [2]. Hence, it has been reported as a promising adsorbent to remove organic molecules such as methylene blue [3], phenol [4], pentachlorophenol [5] and methyl orange [6] from aqueous solu-

\footnotetext{
* Corresponding Author.

Email: argokhoirulanas@uii.ac.id (A.K. Anas)

Telp: +62-74-895920 ext 3012, Fax: +62-74-896439
}

tion. Biochar is an interesting adsorbent material due to its use is correlated with biomass waste utilization and also minimize environmental pollution from high amount of biomass by-product.

Biochar can be produced from various biomass waste such as peanut shell [7], coconut husk [8], corn stalk [9], banana peel [10] and sugarcane bagasse [11]. Moreover, Cassava peel (Manihot utilissima) is another potential biomass waste that can be used as a feedstock for biochar preparation. It is one of the most important agricultural commodities in Indonesia which usually used as a raw material in traditional food production and cassava starch indus- 
tries. The use of cassava produces large amounts of cassava peel waste, and direct dispose of this solid waste can cause environmental problems [12]. Hence, the use of cassava peels as a raw material in biochar preparation is being interesting.

In order to improve the biochar capacity in adsorbing of organic molecules, several surface modifications have been developed, one of them is modification using surface active agent (surfactant). There are several types of surfactants including anionic, cationic and non-ionic surfactants. In previous studies, ionic surfactant exhibited a great potential for biochar modification due to the altering of biochar surface charge. It has been reported that cationic surfactant, cetyltrimethylammonium bromide (CTAB), successfully improved the efficiency of cornstalk biochar to adsorb orange II anionic dye. The use of CTAB could generate positive charge on biochar surface which especially leads to increase orange II adsorption [13]. Furthermore, anionic surfactant, sodium dodecyl sulphate (SDS) was used to modify biochar from peanut shell for methylene blue (MB) adsorption. The attachment of SDS could enhance the negative charges on the biochar surface, which also improve the adsorption of $\mathrm{MB}$ through electrostatic interaction [14]. Regarding to anionic surfactant, sodium dodecyl benzene sulfonate (SDBS) is another potential surfactant that can be used as modifier for biochar surface. SDBS has been applied as coating agent for natural bentonite [15] and hydrotalcites [16] to remove cationic pollutant from aqueous solution.

Both of SDS and SDBS surfactant have similar molecular structure, but different in the presence of phenyl ring in SDBS tail structure (the chemical structures were presented in Table 1). Previous reported study has shown that the adsorption of cationic dye onto biochar is primary controlled by two mechanism including electrostatic and $\pi-\pi$ interactions [17]. In this case, electrostatic interaction is occurred between negative charge of biochar and positive charge of cationic dye [18], which can be improve by attaching anionic surfactant on biochar surface. On the other hand, the presence of $\pi-\pi$ interactions is proposed as another important factor promoting the exceptional performance of biochar in adsorbing cationic dyes especially that contain aromatic moiety in their chemical structure [19].

The surfactant containing phenyl ring can act as surface activating group to adsorb various aromatic pollutant specifically through $\Pi-\Pi$ interaction. To observe the importance of the phenyl ring in surfactant chains, preliminary study of its role in improving biochar ability to adsorb cationic dye is very important. However, a few researchers focused on biochar modification using a surfactant containing phenyl ring in its chain. There have been limited studies concerned on the study in surfactants containing phenyl rings used to activate the biochar surface to adsorb cationic dye in waste water treatment. Therefore, this research intends to enrich the additional understanding of MB adsorption on biochar through $\pi-\pi$ interactions, here is presented a preliminary study of biochar modification using SDBS surfactant which then used as MB adsorbent.

Our previous study have reported biocharSDS preparation and showed that the using of SDS surfactant significantly enhanced the ability of biochar in MB adsorption, especially through electrostatic attraction mechanism [20]. By comparing SDS and SDBS surfactants, it will identify that the adsorption of MB could be significantly increased by the presence of $\pi-\pi$ interactions mechanisms. This finding provides another choice in biochar modification aimed to adsorb aromatic compound pollutant specifically through $\pi-\pi$ interactions using surfactant as a biochar modifier. The objectives of this research are to identity the characterization of biochar-SDBS by using Fourier transform infrared (FTIR), CHNS elemental analysis, and scanning electron microscope (SEM).

Table 1. The chemical structure of anionic surfactant used for biochar modification and compared in this study.

Surfactant name
Sodium dodecyl sulfate (SDS)
$\begin{aligned} & \text { Sodium dodecyl benzene sulfonate } \\ & \text { (SDBS) }\end{aligned}$


In addition, we will also observe the important of phenyl ring on surfactant chain by comparing SDS and SDBS surfactant performance in biochar modification.

\section{Materials and Methods}

\subsection{Materials}

Cassava peels as raw material for biochar preparation were collected from Yogyakarta, Indonesia. Phosphoric acid (Merck, 85\%), methylene blue (Sigma Aldrich, 90\%), and SDBS (Sigma Aldrich, technical grade) were used as received without further purification process. The distilled water was used for preparing working solutions.

\subsection{Preparation of Adsorbent}

The cassava peels were rinsed using water to remove the impurities, dried and cut into small pieces. The prepared cassava peel was pyrolyzed using temperature of $300{ }^{\circ} \mathrm{C}$ in one hour. Biochar powder was then treated using phosphoric acid with concentration of $14 \%$. The treated biochar was then mixed with SDBS and shaken at $250 \mathrm{rpm}$ for six hours. The modified biochar was collected by filtration using filter paper, which then followed by drying process at $110{ }^{\circ} \mathrm{C}$ for 1 hour. The resulted products were named as biochar and biochar-SDBS.

\subsection{Characterization of Adsorbent}

The functional group of biochar and biocharSDBS were characterized using Fourier Transform Infra Red (FTIR) spectrometer (Perkin Elmer). Elemental Analyzer (LECO) was used to identify the percentage of carbon (C), hydro-

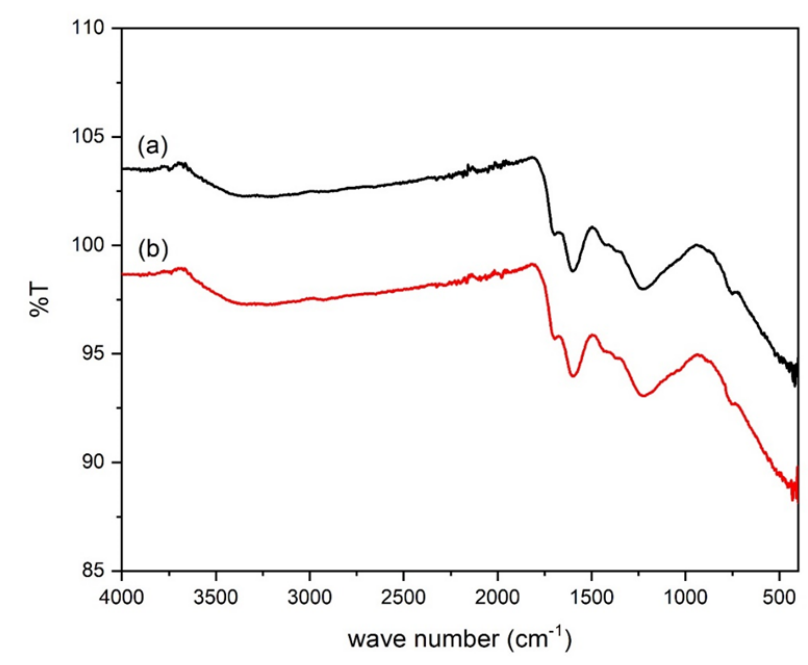

Figure 1. FTIR spectra of (a) biochar and (b) biochar-SDBS. gen $(\mathrm{H})$, nitrogen $(\mathrm{N})$, and sulfur $(\mathrm{S})$. Furthermore, the morphological structures of adsorbents were observed using Scanning Electron Microscope (SEM) JEOL JSM 6510 LA.

\subsection{Methylene Blue Adsorption Experiment}

Biochar and biochar-SDBS with amount of $0.125 \mathrm{~g}$ were added in desired concentration of MB solution $(25 \mathrm{~mL})$. Adsorption experiments were conducted in a shaker at $250 \mathrm{rpm}$ in the room temperature. After 1 hour of mixing process, the mixture was then separated using filter paper. In order to improve the adsorption capacity of biochar, a fixed amount of biochar $(1 \mathrm{~g})$ was mixed with various amount of SDBS surfactant $(0,3,6,9,12$, and $15 \mathrm{mg})$. In addition, the adsorption behavior of adsorbents was investigated at various $\mathrm{pH}$ such as $2,4,7,10$, and 12 .

MB concentration was analyzed using UVVis spectrophotometer at the wavelength of $663 \mathrm{~nm}$. The adsorption capacity $\left(q_{e}\right)$ of biochar, biochar-SDS, and biochar-SDBS were calculated using Equation (1).

$$
q_{e}=\frac{\left(C_{0}-C_{e}\right) V}{m}
$$

where $q_{e}(\mathrm{mg} / \mathrm{g})$ is the amount of $\mathrm{MB}$ adsorbed onto adsorbent; $C_{0}(\mathrm{mg} / \mathrm{L})$ is the MB concentration at initial time; $C_{e}(\mathrm{mg} / \mathrm{L})$ is the MB concentration at final time; $V(\mathrm{~L})$ is the volume of solution and $m(\mathrm{~g})$ is the mass of adsorbent.

\section{Results and Discussion}

\subsection{FTIR Analysis}

FTIR spectroscopy was used to analyse the functional group vibrations in adsorbent [21]. FTIR spectra of biochar and biochar-SDBS are presented in Figure 1. The characterization band of biochar and biochar-SDBS that presents at $3224 \mathrm{~cm}^{-1}$ is attributed to the stretching vibration of $-\mathrm{OH}$ groups, which are attached on the biochar surface. The bands appear at $1598 \mathrm{~cm}^{-1}$ and $1327 \mathrm{~cm}^{-1}$ are ascribed to the stretching vibration of $\mathrm{C}=\mathrm{C}$ and $\mathrm{S}=\mathrm{O}$, re-

Table 2. The element content of biochar and biochar-SDBS resulted from elemental analyzer.

\begin{tabular}{lcccc}
\hline \multirow{2}{*}{ Sample } & \multicolumn{4}{c}{ Element content (\%) } \\
\cline { 2 - 5 } & $\mathrm{C}$ & $\mathrm{H}$ & $\mathrm{N}$ & $\mathrm{S}$ \\
\hline Biochar & 64.13 & 3.65 & 1.89 & 0.23 \\
Biochar-SDBS & 64.92 & 3.54 & 1.89 & 0.22 \\
\hline
\end{tabular}


spectively. Meanwhile, the band at $1223 \mathrm{~cm}^{-1}$ in the both of samples were attributed to $\mathrm{C}-\mathrm{O}$ stretching.

\subsection{CHNS Analysis}

CHNS analysis was performed by CHNS elemental analyzer and the percentage of $\mathrm{C}, \mathrm{H}$, $\mathrm{N}$, and $\mathrm{S}$ contained in of biochar and biocharSDBS are listed in Table 2. It is known that the addition of SDBS surfactant generate an improvement in the carbon content of biochar from $64.13 \%$ to $64.92 \%$. The improvement of carbon percentage could be identified as a consequence of the SDBS surfactant attachment onto biochar surface. On the other hand, the amount of nitrogen presence almost constant, while the percentage of hydrogen and sulphur decreases from $3.65 \%$ to $3.54 \%$ and $0.23 \%$ to $0.22 \%$, respectively. Results obtained in this study are similar to the previous reported study on $\mathrm{C}, \mathrm{H}, \mathrm{N}$, and $\mathrm{S}$ analysis with other type of biochar and anionic surfactant [14].
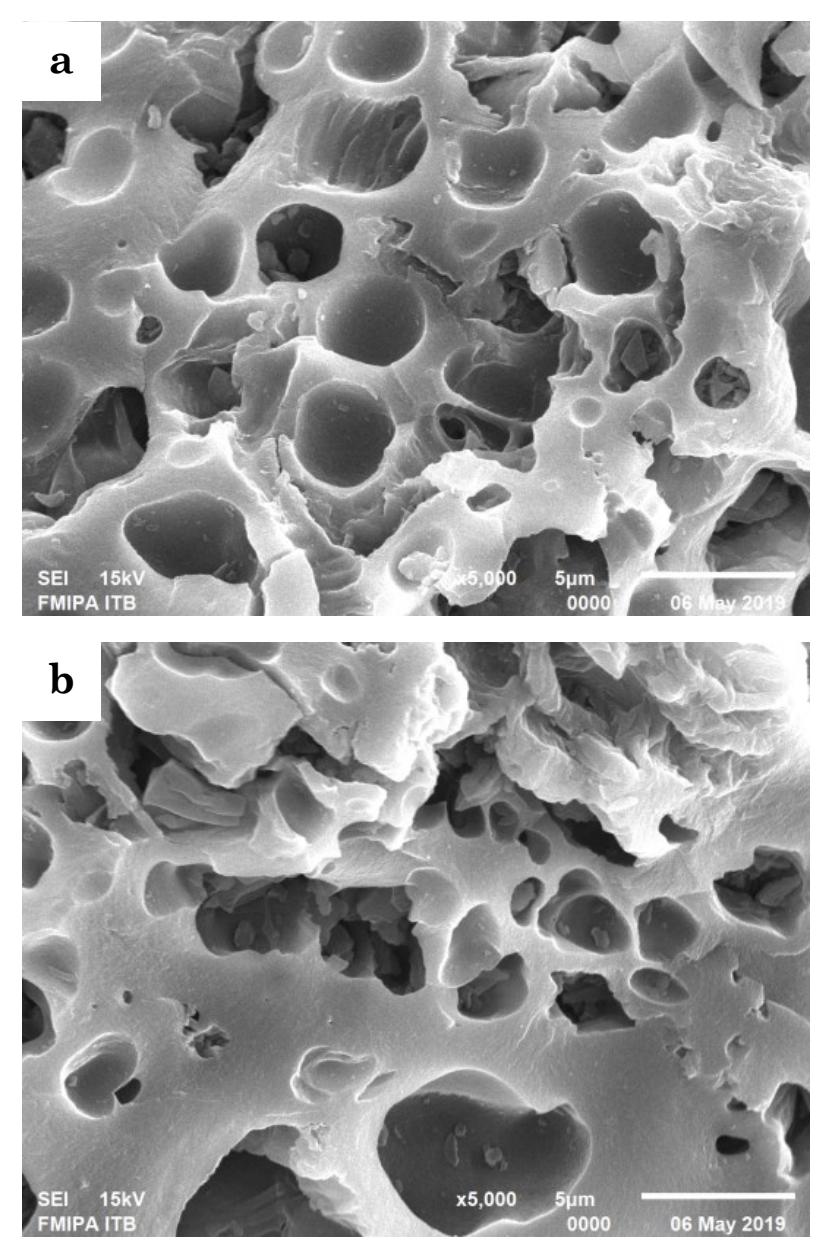

\subsection{SEM Analysis}

The surface physical morphology of biochar and biochar-SDBS were observed by using SEM. As presented in Figure 2, it can be observed that biochar has a regular surface morphology. On the other hand, biochar-SDBS has a rough surface due to they are partially covered by SDBS molecules. It is can be known that modification process using SDBS surfactant could influence the morphologies of biochar and also exhibit more active sites for MB adsorption.

\subsection{Methylene Blue Adsorption}

\subsubsection{Effect of surfactant mass}

In order to increase the adsorption capacities of biochar, various mass of SDS and SDBS were used including $3,6,9,12$, and $15 \mathrm{mg}$. As can be seen in Table 3 and Figure 3, the maximum MB adsorption onto biochar-SDS and biochar-SDBS occurred at adsorbent mass of 15
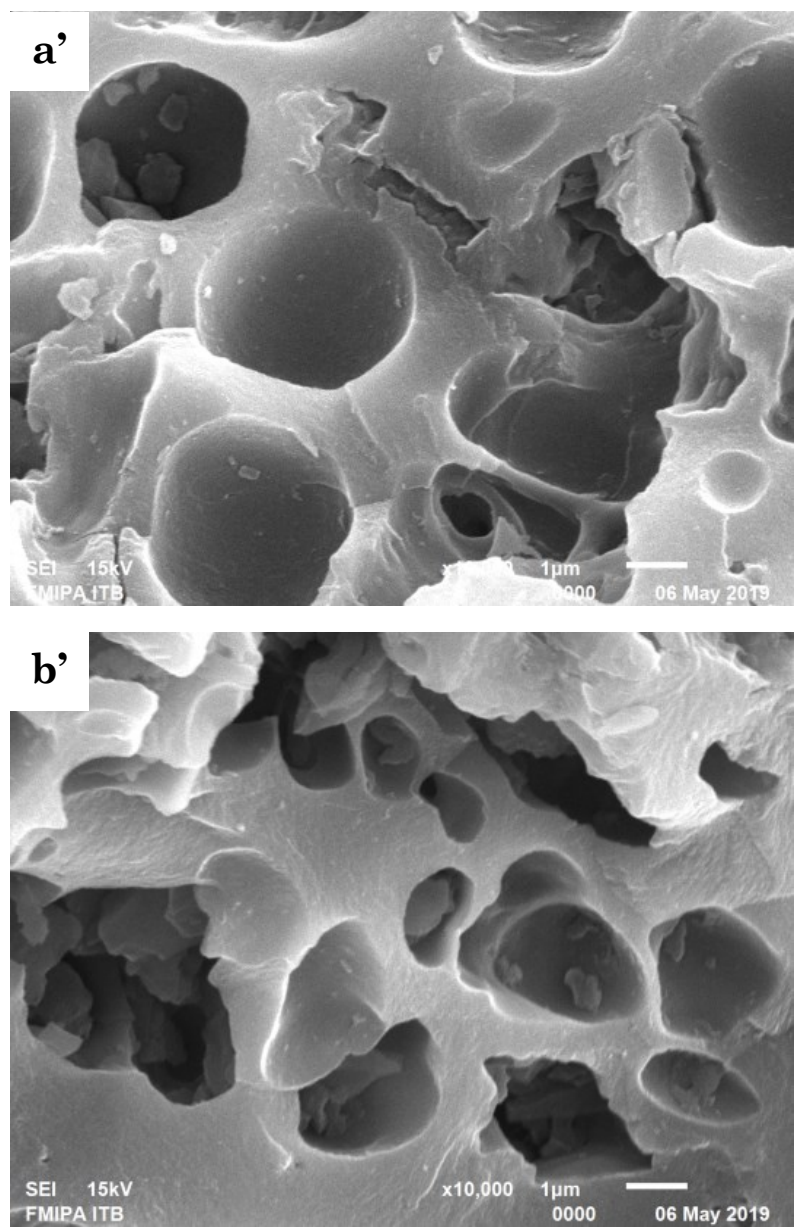

Figure 2. SEM micrographs of (a and a') biochar and (b and b') Biochar-SDBS with different magnification. 
mg. In addition, compared by using pristine biochar, the adsorption capacities were significantly influenced by the mass of SDS and SDBS added. It is also identified that the adsorption capacity of biochar increased as the mass of surfactant increased. The improvement in the MB uptake capacity with the increase of the surfactant mass was due to the improvement of binding sites for adsorption. Importantly, the result of MB adsorption capacities generated by biochar-SDBS was higher than biochar-SDS in all range mass variation, indicating that the use of biochar-SDBS was better than biochar-SDS.

\subsubsection{Effect of $\mathrm{pH}$ solution}

The solution $\mathrm{pH}$ is an important factor affecting the adsorption capacity of adsorbent in wastewater treatment [22]. The adsorption behavior of biochar-SDS and biochar-SDBS was investigated at various $\mathrm{pH}$ including $2,4,7,10$, and 12. As can be seen in Table 4 and Figure 4,

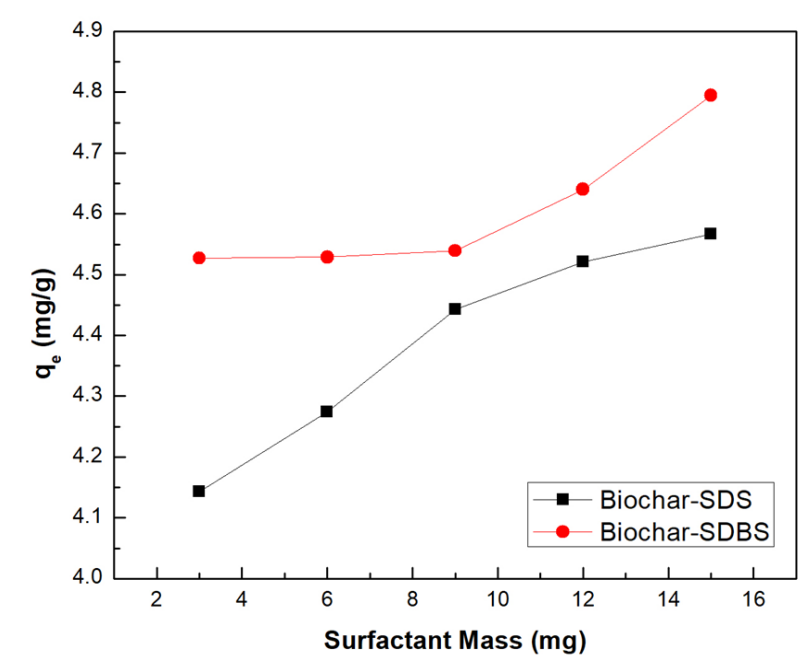

Figure 3. The effect of surfactant mass on MB adsorption using pristine biochar, biochar-SDS and biochar-SDBS. with $\mathrm{pH}$ improvement from 2 to 10, the adsorption capacity of biochar-SDS and biochar-SDBS for MB increased from 2.0754 to $4.9312 \mathrm{mg} / \mathrm{g}$ and 2.197 to $4.945 \mathrm{mg} / \mathrm{g}$, respectively. From these result, it is known that the optimum adsorption capacity of biochar-SDBS was resulted in alkaline condition, similar results were reported by various authors [23]. In this case, alkaline condition will uptake of more cationic molecules due to reduced electrostatic repulsion between biochar and MB [24]. From the results of $\mathrm{MB}$ adsorption onto biochar in $\mathrm{pH}$ variation, it is also observed that biocharSDBS generates better adsorption capacities than biochar-SDS in MB adsorption, which occurred in $\mathrm{pH}$ of $2,4,10$, and 12 .

As can be seen in Figure 3 and Figure 4, it can be further identified that in the surfactant mass and $\mathrm{pH}$ variation biochar-SDBS had better adsorption capacities compared to biocharSDS. These results revealed that phenyl ring on SDBS surfactant chain could improve the

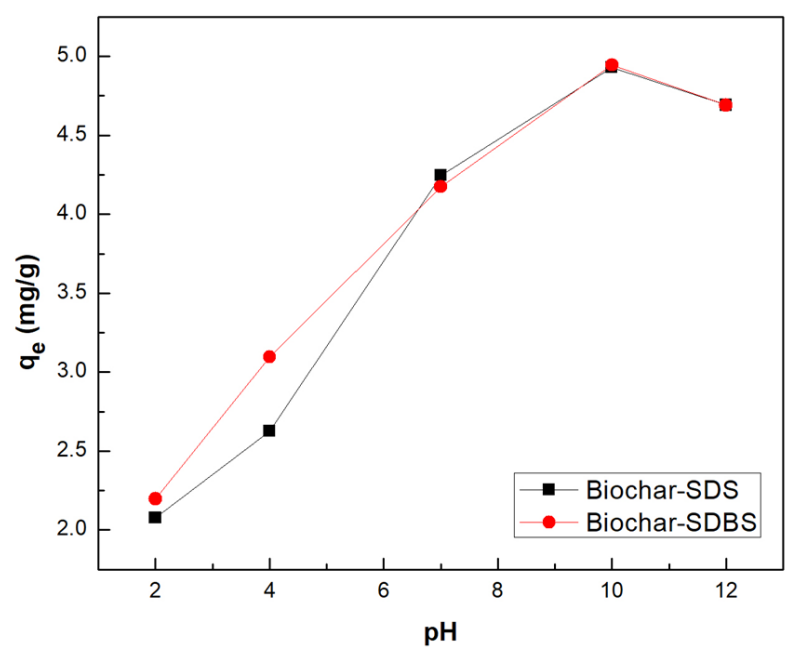

Figure 4. The effect of $\mathrm{pH}$ variation on $\mathrm{MB}$ adsorption using biochar-SDS and biocharSDBS.

Table 3. The Effect of SDS and SDBS surfactant mass on MB adsorption.

\begin{tabular}{lcccccc}
\hline \multirow{2}{*}{ Sample } & \multicolumn{7}{c}{ Surfactant mass (mg) } \\
\cline { 2 - 7 } & 0 & 3 & 6 & 9 & 12 & 15 \\
\hline Biochar-SDS & 4.0721 & 4.1432 & 4.2742 & 4.4427 & 4.5213 & 4.5672 \\
Biochar-SDBS & 4.0721 & 4.5269 & 4.5288 & 4.5391 & 4.6401 & 4.7946 \\
\hline
\end{tabular}

Table 4. The Effect of $\mathrm{pH}$ on MB adsorption.

\begin{tabular}{lccccc}
\hline \multirow{2}{*}{ Sample } & \multicolumn{5}{c}{$\mathrm{pH}$} \\
\cline { 2 - 6 } & 2 & 4 & 7 & 10 & 12 \\
\hline Biochar-SDS & 2.0754 & 2.6276 & 4.2443 & 4.9312 & 4.6907 \\
Biochar-SDBS & 2.1970 & 3.0955 & 4.1741 & 4.9452 & 4.6916 \\
\hline
\end{tabular}


MB adsorption through $\pi-\pi$ interactions. In order to demonstrate the importance of phenyl ring on $\mathrm{MB}$ adsorption, the proposed illustration of interaction between biochar-SDS and biochar-SDBS with MB molecules is presented in Figure 5. In this case, non-polar tail of SDS and SDBS can attach to the biochar surface via hydrophobic interaction [25], hence the polar head of SDS and SDBS that contain negative charge of sulfonate group are located to the biochar surface. As a consequence, surfactant attached on to the surface caused more negative site on biochar, which then enhancing the electrostatic attraction between biochar and MB. Focusing in case of biochar-SDBS, MB adsorption can be improved through $\pi-\pi$ interactions between aromatic group in SDBS and MB molecular structure.

\section{Conclusions}

This study verified the feasibility of SDBS for modification of biochar applied in MB dyes adsorption. Modification using SDBS successfully improved the adsorption capacity of biochar for MB. As the amount of SDBS mass increased, the adsorption capacity increased because the modification produced more negative group on the biochar, while the optimum adsorption capacity was resulted in alkaline condition. Interestingly, by comparing the performance of SDS and SDBS surfactants in biochar modification, it can be proven that the adsorption of MB could be significantly increased by the presence of $\pi-\pi$ interactions mechanisms. This result suggests the important of phenyl ring on surfactant tail structure used for biochar modification, specifically for adsorption of pollutant compound that contain $\pi$ system in their molecular structure.

\section{Acknowledgments}

The authors thank the Direktorat Penelitian dan Pengabdian Masyarakat (DPPM), Universitas Islam Indonesia, for the financial support in this research project.

\section{References}

[1] Meyer, S., Glaser, B., Quicker, P. (2011). Technical, economical, and climate-related aspects of biochar production technologies: a literature review. Environmental Science \& Technology, 45(22), 9473-9483, doi: 10.1021/es201792c.

[2] Giorcelli, M., Khan, A., Pugno, N.M., Rosso, C., Tagliaferro, A. (2019). Biochar as a cheap and environmental friendly filler able to improve polymer mechanical properties. Biomass and Bioenergy, 120, 219-223, doi: 10.1016/j.biombioe.2018.11.036.

[3] Fan, S., Wang, Y., Wang, Z., Tang, J., Tang, J., Li, X. (2017). Removal of methylene blue from aqueous solution by sewage sludgederived biochar: Adsorption kinetics, equilibrium, thermodynamics and mechanism. Journal of Environmental Chemical Engineering, 5(1), 601-611, doi: 10.1016/j.jece.2016.12.019.

[4] Mohammed, N.A., Abu-Zurayk, R.A., Hamadneh, I., Al-Dujaili, A.H. (2018). Phenol adsorption on biochar prepared from the pine fruit shells: Equilibrium, kinetic and thermodynamics studies. Journal of Environmental Management, 226, 377-385, doi: 10.1016/j.jenvman.2018.08.033.

[5] Devi, P., Saroha, A.K. (2014). Synthesis of the magnetic biochar composites for use as an adsorbent for the removal of pentachlorophenol from the effluent. Bioresource Technology, $169, \quad 525-531, \quad \mathrm{~d}$ o i : 10.1016/j.biortech.2014.07.062.

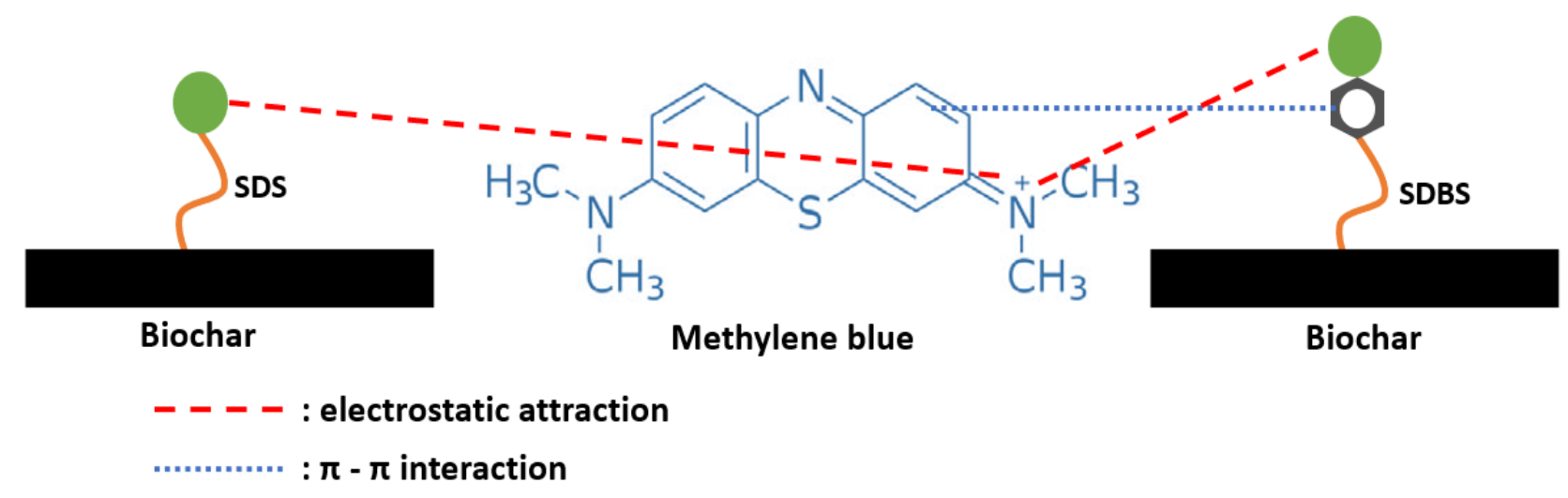

Figure 5. The schematic of interaction between biochar-SDS and biochar-SDBS with methylene blue. 
[6] Yang, L., Gao, J., Liu, Y., Zhang, Z., Zou, M., Liao, Q., Shang, J. (2018). Removal of methyl orange from water using sulfur-modified nZVI supported on biochar composite. Water, Air, \& Soil Pollution, 229(11), 355, doi: 10.1007/s11270-018-3992-x.

[7] Sattar, M.S., Shakoor, M.B., Ali, S., Rizwan, M., Niazi, N.K., Jilani, A. (2019). Comparative efficiency of peanut shell and peanut shell biochar for removal of arsenic from water. Environmental Science and Pollution Research, 26(18), 18624-18635, doi: 10.1007/s11356-019-05185-z.

[8] Suman, S., Gautam, S. (2017). Pyrolysis of coconut husk biomass: Analysis of its biochar properties. Energy Sources, Part A: Recovery, Utilization, and Environmental Effects, 39(8), 761-767,

doi: 10.1080/15567036.2016.1263252.

[9] Yang, F., Zhang, S., Sun, Y., Cheng, K., Li, J., Tsang, D.C. (2018). Fabrication and characterization of hydrophilic corn stalk biocharsupported nanoscale zero-valent iron composites for efficient metal removal. Bioresource Technology, 265, 490-497, doi: 10.1016/j.biortech.2018.06.029.

[10] Rong, X., Xie, M., Kong, L., Natarajan, V., Ma, L., Zhan, J. (2019). The magnetic biochar derived from banana peels as a persulfate activator for organic contaminants degradation. Chemical Engineering Journal, 372, 294-303, doi: 10.1016/j.cej.2019.04.135.

[11] Nie, C., Yang, X., Niazi, N.K., Xu, X., Wen, Y., Rinklebe, J., Ok, Y.S., Xu, S., Wang, H. (2018). Impact of sugarcane bagasse-derived biochar on heavy metal availability and microbial activity: a field study. Chemosphere, $200, \quad 274-282, \quad \mathrm{~d}$ o i : 10.1016/j.chemosphere.2018.02.134.

[12] Sudaryanto, Y., Hartono, S., Irawaty, W., Hindarso, H., Ismadji, S. (2006). High surface area activated carbon prepared from cassava peel by chemical activation. Bioresource Technology, $97(5), \quad 734-739, \quad$ doi: 10.1016/j.biortech.2005.04.029.

[13] Mi, X., Li, G., Zhu, W., Liu, L. (2016). Enhanced adsorption of orange II using cationic surfactant modified biochar pyrolyzed from cornstalk. Journal of Chemistry, 2016, 8457030, doi: 10.1155/2016/8457030.

[14] Que, W., Jiang, L., Wang, C., Liu, Y., Zeng, Z., Wang, X., Ning, Q., Liu, S., Zhang, P., Liu, S. (2018). Influence of sodium dodecyl sulfate coating on adsorption of methylene blue by biochar from aqueous solution. Journal of Environmental Sciences, 70, 166-174, doi: 10.1016/j.jes.2017.11.027.
[15] Ab Kadir, N.N., Shahadat, M., Ismail, S. (2017). Formulation study for softening of hard water using surfactant modified bentonite adsorbent coating. Applied Clay Science, 137, 168-175, doi: 10.1016/j.clay.2016.12.025.

[16] Bouraada, M., Ouali, M.S., de Menorval, L.C. (2016). Dodecylsulfate and dodecybenzenesulfonate intercalated hydrotalcites as adsorbent materials for the removal of BBR acid dye from aqueous solutions. Journal of Saudi Chemical Society, 20(4), 397-404, doi: 10.1016/j.jscs.2012.07.009.

[17] Ahmed, M.B., Zhou, J.L., Ngo, H.H., Johir, M.A.H., Sun, L., Asadullah, M., Belhaj, D. (2018). Sorption of hydrophobic organic contaminants on functionalized biochar: Protagonist role of $\pi-\pi$ electron-donor-acceptor interactions and hydrogen bonds. Journal of Hazardous Materials, 360, 270-278, doi: 10.1016/j.jhazmat.2018.08.005.

[18] Jawad, A.H., Abdulhameed, A.S., Mastuli, M.S. (2020). Acid-factionalized biomass material for methylene blue dye removal: a comprehensive adsorption and mechanism study. Journal of Taibah University for Science, 14 ( 1 ), $\quad 305-313, \quad \mathrm{~d}$ o i : 10.1080/16583655.2020.1736767.

[19] Hoslett, J., Ghazal, H., Mohamad, N., Jouhara, H. (2020). Removal of methylene blue from aqueous solutions by biochar prepared from the pyrolysis of mixed municipal discarded material. Science of the Total Environment, $\quad 714, \quad 136832, \quad \mathrm{~d}$ o i : 10.1016/j.scitotenv.2020.136832.

[20] Anas, A.K., Izzah, A., Pratama, S.Y., Fajarwati, F.I. (2020). Removal of methylene blue using biochar from cassava peel (Manihot utilissima) modified by sodium dodecyl sulphate (SDS) surfactant. AIP Conference Proceedings, 2229(1), 030024, doi: 10.1063/5.0002675.

[21] Ali, S., Rizwan, M., Shakoor, M.B., Jilani, A., Anjum, R. (2020). High sorption efficiency for As (III) and As (V) from aqueous solutions using novel almond shell biochar. Chemosphere,

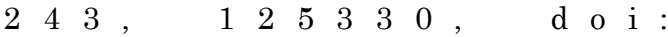
10.1016/j.chemosphere.2019.125330.

[22] Gulnaz, O., Kaya, A., Matyar, F., Arikan, B. (2004). Sorption of basic dyes from aqueous solution by activated sludge. Journal of Hazardous Materials, 108(3), 183-188, doi: 10.1016/j.jhazmat.2004.02.012.

[23] Liu, Y., Zhao, X., Li, J., Ma, D., Han, R. (2012). Characterization of bio-char from pyrolysis of wheat straw and its evaluation on methylene blue adsorption. Desalination and Water Treatment, 46(1-3), 115-123, doi: 10.1080/19443994.2012.677408. 
[24] Wang, S., Zhu, Z., Coomes, A., Haghseresht, F., Lu, G. (2005). The physical and surface chemical characteristics of activated carbons and the adsorption of methylene blue from wastewater. Journal of Colloid and Interface Science, 284(2), 440-446, doi: 10.1016/j.jcis.2004.10.050
[25] Lu, L., Zhu, L. (2012). Effect of soil components on the surfactant-enhanced soil sorption of PAHs. Journal of Soils and Sediments, 12(2), 161-168, doi: 10.1007/s11368-0110432-6.

Selected and Revised Papers from $3^{\text {rd }}$ International Conference on Chemistry, Chemical Process and Engineering 2020 (IC3PE 2020) (https://chemistry.uii.ac.id/ic3pe/) (Universitas Islam Indonesia (UII), Labuan Bajo, Nusa Tenggara Timur, Indonesia by $30^{\text {th }}$ September - $1^{\text {st }}$ October 2020) after Peer-reviewed by Scientific Committee of IC3PE 2020 and Peer-Reviewers of Bulletin of Chemical Reaction Engineering \& Catalysis.

Editors: I. Istadi; Is Fatimah 